\title{
Oddity learning in rats reinforced with brain stimulation'
}

ROGER N. JOHNSON ${ }^{2}$ AND RONALD S. LEVY, DEPARTMENT OF PSYCHOLOGY, AMHERST COLLEGE, Amherst, Mass. 01002

In massive training sessions using intracranial reinforcement, four rats reached $70-80 \%$ correct in three-position simple oddity learning. Results suggest that Ss learned specific configurations rather than an oddity principle.

Comparative studies of oddity learning have of ten been heroic efforts meeting with little success. Warren (1965) concluded that most cats fail to demonstrate any oddity learning, even after large numbers of trials, and that the few which do show learning fail to transfer an "oddity principle" to new stimuli. Strong \& Hedges (1965) reported high levels of performance in chimpanzees and rhesus monkeys, but after about 5000 trials they failed to find any evidence of oddity learning in cats or raccoons. They concluded that perhaps oddity learning might be an impossible task for any subprimate organism.

Sparse data on rodents appears to support this conclusion. In 1938, Lashley attempted to train rats on a three-position oddity problem and reported that all animals stopped responding altogether or displayed stereotyped response patterns. Wodinsky \& Bitterman (1953) trained two rats to criterion on an odd stimulus, and then reversed the odd stimulus. Using manual guidance following three successive errors, shifts were made relatively quickly after 30 reversals. Then the rats were switched to an oddity procedure in which the odd stimulus was alternated randomly. After four or five transfer problems, both animals showed above chance level performance on the first day of a new problem.

Hudspeth (1964) also used a reversal training procedure in a three-choice shock avoidance task. After 25 days ( 300 trials) six Ss failed to demonstrate any oddity learning; however, six Ss given post-trial injections of strychnine sulphate performed slightly above chance level on the last few days.

Since these experiments varied extensively in procedure it is difficult to evaluate them, except to conclude that rodents and carnivores generally fail to learn with straight oddity procedures. However, special training conditions, such as going from an easy to hard sequence or using drugs, may indicate a capacity for oddity learning. Because such data may reveal more about the testing capacity of conventional procedures than about learning capacity of animals, the present experiment was designed to make use of the massive training procedures possible with intracranial stimulation (ICS). Previous work (Johnson, 1966) indicated that with ICS, rats could form pattern discrimination learning sets which conventional procedures had failed to demonstrate. Because of the great number of trials necessary to learn pattern discriminations with ICS, the present experiment was designed to test simple oddity learning using light and dark stimuli.

Subjects. Four male Charles River albino rats, $250-300$ days old, were stereotaxically implanted with bipolar electrodes, .014 in. in diameter. Histology showed the electrode tips to be in the lateral hypothalamus and medial forebrain bundle. Rats 9 and 14 had previously learned about 70 brightness reversals with ICS in a different apparatus while Ss 106 and 107 were experimentally naive.

Apparatus. The front of the experimental chamber contained three translucent response panels, 3.5 in. square, with the two side panels angled slightly to make all three equidistant from the middle of the apparatus. The six possible configurations of two light and one dark or two dark and one light were provided by lights behind the panels. A repeating series of 60 random presentations of the configurations was programmed by an Actan stepper.

Procedure. In preliminary training, all panels were dimly illuminated and Ss were reinforced for panel pressing on a VR 3 schedule. After several hundred trials Ss were shifted directly to the randomly presented configurations of light and dark stimuli. Correct responses were reinforced with $0.5 \mathrm{sec}$ of 60 cycle current stepped down with a Variac and presented through a series resistance (for monitoring on a CRO) via a mercury swivel. An incorrect response operated a buzzer behind the panels. Rats were run 2000-5000 trials per day with an intertrial interval of $2.5 \mathrm{sec}$ on a noncorrection procedure. The apparatus was dark during the intertrial interval with the stimuli coming on $0.5 \mathrm{sec}$ before the response panels were activated and remaining on $0.5 \mathrm{sec}$ after each response, thus assuring a minimum of $1.0 \mathrm{sec}$ stimulus exposure per trial. The number of correct responses was printed out every 1000 trials. Detailed analysis of the response patterns was carried out on the naive rats (106 and 107) by monitoring them on closed circuit TV and recording all responses and stimuli for a randomly selected block of 120 trials (20 presentations of each configuration) each day.

Results and Discussion. Figure 1 shows clear evidence of learning for all Ss, with the naive animals learning more slowly and reaching a slightly lower asymptote (about $70 \%$ ) than the Ss with previous reversal experience (about $80 \%$ ). Long strings of correct responses (the longest being 45) were not uncommon toward the end of the experiment. Late in training, all Ss required increased levels of ICS to maintain responding. When Ss failed to respond at all, presumably due to lesions created by the massive stimulation, the experiment was terminated. It can be noticed that performance levels tended to fall off in these later stages.

An analysis of response patterns of the naive rats was made by arbitrarily selecting the early training sessions (where performance varied between $30-45 \%$ correct) and comparing them with training sessions when performance was at asymptote. In early learning, an overall $F$ test indicated significant differences in accuracy of responding to particular configurations $(F=9.88$, df $=5 / 5$, $\mathrm{p}<.05$ ). A Newman-Keuls test on differences between pairs of means showed that performances on configurations DDL and LLD were both significantly $(\mathrm{p}<.05)$ better when compared to DLD and LDL. (See Table 1.)

When Ss were at asymptote, an $F$ test again showed that performance level was significantly related to particular configurations $(F=9.23$, of $=5 / 5, p<.05)$. Comparison tests indicated that performance on configuration DDL was significantly $(\mathrm{p}<$ .05) better than performance on LLD, DLL, DLD, and LDL. Significance was approached $(p<.06)$ when comparing LDD to LLD, DLL, and DLD.

While animals showed no major stimulus preference ( $54 \%$ of all responses to the light stimulus), they did have a tendency to respond most frequently to the right panel and least to the middle panel. This might be related to previous findings (Moon \& Harlow, 1955) that configurations with the odd object in the middle are most difficult. Late in training, however, animals responded about equally often to all three panels.

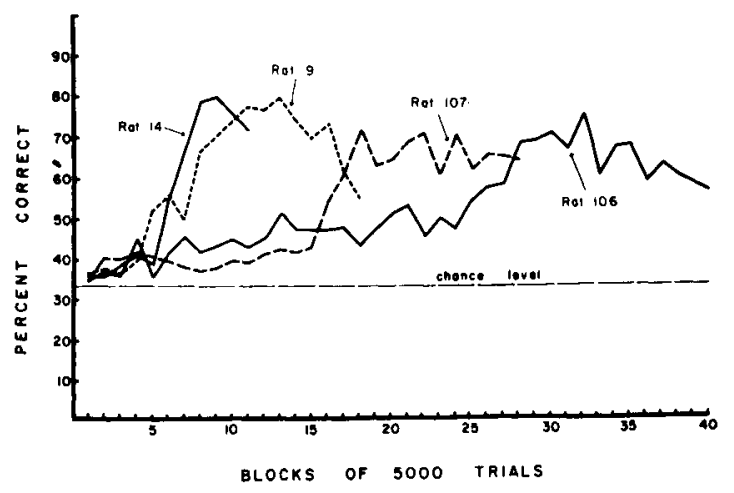

Fig. 1. Overall per cent correct for 1,000 to 200,000 trials. 
Table 1

Mean Per Cent Correct for Each Configuration of Light (L) and Dark (D) Stimuli in Early and Late Training Sessions

\begin{tabular}{lccccccc} 
& RAT & LDD & DDL & LLD & DLL & DLD & LDL \\
\hline EARLY & 106 & 41.25 & 61.71 & 61.41 & 35.63 & 36.56 & 16.01 \\
LEARNING & 107 & 45.68 & 66.14 & 66.14 & 37.27 & 13.18 & 11.26 \\
LATE & 106 & 71.94 & 81.61 & 62.90 & 56.13 & 55.48 & 67.10 \\
LEARNING & 107 & 83.00 & 90.00 & 52.00 & 49.00 & 55.00 & 62.00 \\
\hline
\end{tabular}

The evidence obtained suggests that the rats eventually performed well by mastering particular configurations. Early in learning, overall performance slightly above chance level was due to substantial learning of configurations DDL and LLD combined with chance level performance on other configurations. Later in learning, very good performance on DDL and LDD combined with moderately accurate performance on the other patterns to produce asymptotes of about $70 \%$. It appears that some configurations were more readily learned than others, as if there were six separate problems rather than one. If an "oddity principle" had been learned, presumably the animals would be about equally accurate on all configurations.

These data, then, demonstrate that while it is possible for rats to do relatively well on oddity problems, there is no evidence that they do so by adopting an abstract oddity principle. If future research develops a more efficient ICS training procedure, patterned stimuli and transfer tests might be used which could test this point more effectively.

\section{REFERENCES}

HUDSPETH, W. J. Strychnine: Its facilitating effect on the solution of a simple oddity problem by the rat. Science, 1964, 145, 1331-1333.

JOHNSON, R. N. Pattern discrimination learning set formation in albino rats with brain stimulation as a reinforcer. Psychon. Sci, 1966, 6, 315-316.

LASHLEY, K. S. The mechanism of vision: XV. Preliminary studies of rat's capacity for detail vision. J. gen. Psychol., 1938, 18, 123-193.

MOON, L. E., \& HARLOW, H. F. Analysis of oddity learning by rhesus monkeys. J. comp. physiol Psychol, 1955, 48, 188-195.

STRONG, P. S., \& HEDGES, M. Comparative studies in simple oddity learning: I. Cats, raccoons, monkeys, and chimpanzees. Psychon. Sci, $1966,5,13-14$

WARREN, J. M. Primate learning in comparative perspective. In A. M. Schrier, H. F. Harlow, \& F. Stollnitz (Eds.), Behavior of nonhuman primates. New York: Academic Press, 1965. Pp. 248-281.

WODINSKY, J., \& BITTERMAN, M. E. The solution of oddity problems by the rat. Amer. J. Psychol., 1953, 66, 137-140.

\section{NOTES}

1. This research was supported by Grant MH 14060 from the National Institutes of Mental Health. I am grateful to Diane Olson and Thomas Alpren for assistance.

2. Now at Tufts University. 